\title{
Modelos DE ESPACIALIDADE NA OBRA DE RAFAEL COURTOISIE
}

Luis Alberto Brandão

UFMG

\begin{abstract}
RESU M O
A obra do escritor uruguaio Rafael Courtoisie é tomada como ponto de partida para uma reflexão sobre alguns modelos por meio dos quais a literatura contemporânea exercita o que se pode designar, genericamente, de "espacialidade". Esse termo não diz respeito ao modo como o texto literário representa espaços extratextuais. Na verdade, atua na direção contrária, tornando viável que, no âmbito da literatura, se problematize o que é entendido como espaço. Os três modelos de espacialidade que abordamos são: a visão, o tato e o movimento. Da obra de Courtoisie, foram selecionados os seguintes livros: Estado sólido (1996), Umbría (1999) e Música para sordos (2002).
\end{abstract}

\section{PALAVRAS - CHAVE}

Espaço. Espacialidade. Rafael Courtoisie. Literatura contemporânea. Literatura latino-americana.

\begin{abstract}
A obra do escritor uruguaio Rafael Courtoisie é extensa e diversificada. Apresenta, entretanto, como denominador comum irrecusavelmente relevante, a exploração de limites não apenas entre gêneros, mas também, de modo bastante abrangente, entre regimes textuais. Constata-se, por exemplo, além da mescla de narrativa e poesia como gêneros em sentido estrito, o amplo tensionamento recíproco dos regimes literário, científico e filosófico, sobretudo pela aproximação agonística de imagem e conceito. A obra de Courtoisie pode ser tomada como ponto de partida para uma reflexão sobre alguns modelos por meio dos quais a literatura contemporânea (pelo menos a que se compromete com algum grau de ousadia e de busca de possibilidades além das consolidadas) exercita o que propomos designar, genericamente, de "espacialidade".

Esse termo não diz respeito, na leitura aqui empreendida, ao modo como o texto literário representa espaços extratextuais. Na verdade, o termo atua na direção contrária, ou seja, tornando viável que, no âmbito da literatura, se estimule e se vivencie a problematização do que é entendido como espaço. Isso ocorre mediante a crítica ao próprio pressuposto de que a categoria espaço é autoevidente, de que determina a si mesma, ou de que não passa de um dado oferecido passivamente à percepção e à conceptualização. Alguns versos soltos, extraídos de poemas diversos de Courtoisie,
\end{abstract}


demonstram o tipo de problematização a que nos referimos: "Las casas sudan música"; ${ }^{1}$ "Toda Umbría es un arrabal sin centro"; ${ }^{2}$ "Las paredes hablan, sí, un idioma perfectamente vertical cuyo dominio exhiben los reclusos"; 3 e "Una mano de tierra edifica ciudades y relámpagos oscuros". 4

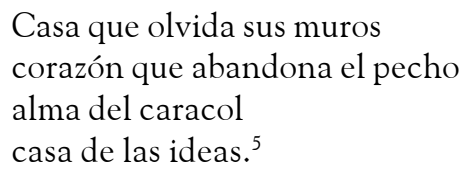

Os três modelos de espacialidade que aqui abordamos são: a visão, o tato e o movimento. Da obra de Courtoisie, da parte desta que se costuma classificar explicitamente como poética, foram selecionados os seguintes livros: Estado sólido, de 1996, Umbría, de 1999, e Música para sordos, de 2002.

Já no título Estado sólido se explicita o modelo do tato, ou do espaço como categoria material. A atribuição de solidez, concretude, materialidade ao signo verbal, e, por extensão, ao texto literário, é, como se sabe, umas das soluções mais comuns nas tentativas de se definir literatura, sobretudo quando se pretende identificar a especificidade do texto poético. Bastaria mencionar a obra de Roman Jakobson, segundo a qual a poesia é a linguagem voltada para a sua própria materialidade; ou a de Roland Barthes, interessado no caráter sensível expresso na noção de significância; ou os vínculos estreitos enfatizados, por Octavio Paz, entre poesia e erotismo. Também é incontornável a menção ao fato de que boa parte da obra de Gaston Bachelard (pensador sobremaneira influente, possivelmente o primeiro nome lembrado quando o assunto em pauta é a relação entre literatura e espaço, devido ao muito difundido A poética do espaço) é dedicada à apologia da "imaginação material", que se rebela contra o racionalismo definidor da "imaginação formal".

A imaginação material pode, com efeito, ser observada em plena ação na obra de Courtoisie, embora de modo peculiar, pois os materiais não são apresentados segundo qualidades supostamente intrínsecas, determinantes de sua "materialidade". Sem dúvida, objetos e eventos com frequência são definidos por meio da atribuição de qualidades ou estados físicos: "Cualquier niño sabe que la alegría es gaseosa y la tristeza líquida. La vida y la muerte pertenecen al estado sólido."

Tais estados, no entanto, comportam matérias que, em princípio, não lhe são afins, ou cuja afinidade não é óbvia. Assim, a solidão é "una fruta de hierro"; ${ }^{7}$ o bronze "simula la carne para desmentirla"; "El silencio, en Umbría, es pesado y falso como una pluma

${ }^{1}$ COURTOISIE. Umbría, p.10.

${ }^{2}$ COURTOISIE. Umbría, p. 50.

${ }^{3}$ COURTOISIE. Estado sólido, p. 13.

${ }^{4}$ COURTOISIE. Umbría, p. 23.

${ }^{5}$ COURTOISIE. Música para sordos, p. 20.

${ }^{6}$ COURTOISIE. Estado sólido, p. 11.

${ }^{7}$ COURTOISIE. Estado sólido, p. 15

${ }^{8}$ COURTOISIE. Estado sólido, p. 20. 
de piedra". ${ }^{9}$ Afirma-se a relevância da matéria mas simultaneamente a imprevisibilidade do vínculo matéria-objeto, o que faz com que a própria noção de objeto seja colocada sob suspeita:

Piensa en las piedras: ese es un buen pensamiento, sólido, estable.

En las piedras que parecen deseos, en las piedras del tiempo que parecen años. ${ }^{10}$

Na obra de Rafael Courtoisie certamente se encontram ecos da preponderância da mão como ícone máximo de uma espacialidade na qual as matérias se tocam, os sujeitos se fundem a objetos físicos ou se constituem por meio destes. A cosmicidade do trabalho artístico pode ser vislumbrada mediante a interação dos corpos em sua concretude, na extremada sensorialidade das superfícies. Entretanto, o vislumbre se elabora de modo crítico e incerto, a contrapelo da pretensão topofílica, arquetipicamente feliz de Gaston Bachelard. A mão é hesitante, quando não desdenhosa; seu labor não é automotivado. Há uma espécie de ceticismo na própria matéria, já que esta parece impedida de acreditar na estabilidade dos arquétipos. No texto "Superficies", se diz: "El horror a la profundidad, el canto del afuera en todas las cosas, esa humedad de piel o esa aspereza de costra, ese murmullo táctil que presenta la materia y que siempre se exhibe."11

O livro Umbría é composto à maneira das utopías, embora obliquamente. Assim, se há um horizonte como possibilidade de arranjo ideal de convivência entre os integrantes de uma sociedade, este horizonte é negativo. Na caracterização de tal universo equivocamente utópico, afirma-se: "Una religión del tacto supera a la religión de la mirada. Las parejas se vendan los ojos y se tocan." ${ }^{12}$ É estimulante pensar a literatura contemporânea (e o modo como ela se configura espacialmente, em termos conceituais e sensoriais) a partir do embate ou negociação entre estas duas "religiões", ou, se preferirmos, estas duas "epistemologias" ou "imaginações": a do tato e a da visão. Os versos que abrem o poema "Vuelo bajo" dizem:

YO QUIERO tocar los ojos, el mundo oscurecido. Las podridas

líneas de la vida. ${ }^{13}$

O espaço configurado/apreendido pela visão é aquele que, em princípio, exige a distância entre o observador e o observado. É esta distância que define a própria nitidez da visibilidade resultante. Tal espaço é prioritariamente o espaço das formas, aparentes ou supostas, e não das matérias, pois um forte componente de abstração (em muitos casos, de idealização) necessariamente está presente. O poema "Tierra firme" explora

${ }^{9}$ COURTOISIE. Umbría, p. 41.

${ }^{10}$ COURTOISIE. Música para sordos, p. 31.

${ }^{11}$ COURTOISIE. Estado sólido, p. 24.

${ }^{12}$ COURTOISIE. Umbría, p. 10.

${ }^{13}$ COURTOISIE. Música para sordos, p. 77. 
as ambivalências entre o tocado e o formalizado, a proximidade e a distância, a percepção e a representação, levando-as ao extremo da relação aporética entre tautologia e indecidibilidade:

Tierra firme

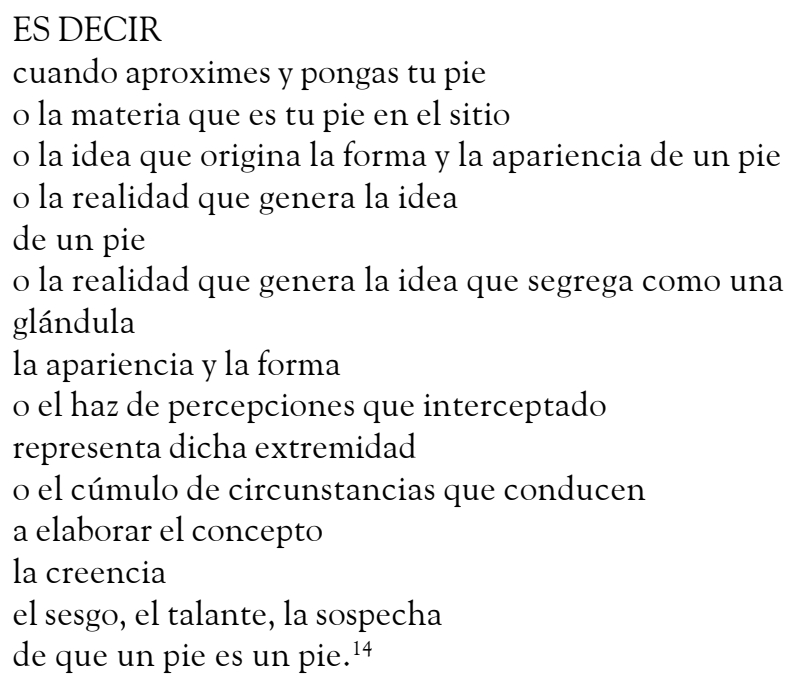

O espaço, entretanto, também pode ser abordado não como categoria de base, determinante de outras categorias, mas como resultante, como um efeito, a momentânea cristalização de processos em estados (que podem se revelar em graus de incerteza maiores ou menores). Espaços podem ser conceituados como efeitos de deslocamentos, o que introduz no cerne do conceito as noções de movimento e de tempo. Em Estado sólido se define: "El fuego es una piedra momentánea" ${ }^{15}$ na série "Crueles", de Umbría, cadáveres de gatos envenenados aparecem nos jardins, mas "son cadáveres aéreos, voladores, puesto que muchos de ellos murieron en el momento del salto, o en el salto mucho mayor del apareamiento, de la cópula". ${ }^{16}$ Também no destaque aos morcegos se percebem os elos instáveis e reversíveis que viabilizam o trânsito entre tato, visão e movimento. Em Umbría, a personagem U vê e toca um morcego:

U estira la mano y desprende esas frutas oscuras, palpitantes en su capullo membranoso, acaricia el terciopelo negro que las cubre, delgado y soberbio como una piel de durazno, pero algo más duro y húmedo, como el recubrimiento de un cuerpo interior en suspensión, como un órgano sin cuerpo.

U siente el ronquido y la respiración tranquila que alcanza todo animal no vidente durante el día, $U$ cosecha esas frutas casi humanas, vivientes, que se parecen al deseo no cumplido. ${ }^{17}$

Também o texto "Palabras de la noche", de Estado sólido, dá ao morcego especial destaque:

${ }^{14}$ COURTOISIE. Música para sordos, p. 97.

${ }^{15}$ COURTOISIE. Estado sólido, p. 8.

${ }^{16}$ COURTOISIE. Umbría, p. 42-43.

${ }^{17}$ COURTOISIE. Umbría, p. 45. 
Un animal volador de la noche confía solamente en las ideas, cavila con sus ojos interiores, avanza por sus pelos.

A cada paso una contestación, el sonido refleja en las paredes que devuelven una mirada de palabras. Reflexiona. El paso del murciélago es puro espíritu, es escritura. ${ }^{18}$

O espaço tátil pode tender a se desmaterializar, tornar-se impalpável, preferencialmente só movimento. Assim é que, utilizando-se expressões cunhadas por Gaston Bachelard, percebe-se que a "imaginação material" cede lugar à "imaginação dinâmica”. Todavia, não se trata apenas de tipos de imaginação passíveis de conviver com alguma harmonia, pois o dinamismo coloca em xeque a própria noção de matéria. Em deslocamento, a materialidade se desmaterializa, o caráter efêmero da matéria é levado ao extremo, a debilidade sobrepuja a condição supostamente substantiva. No texto "Resistencia de materiales" se enuncia enfaticamente: "La debilidad pone su huevo en todo"; "la debilidad, mujer absoluta, abate la erección de bronce de las estatuas masculinas." ${ }^{19}$ Se a mão, ao tocar, é capaz de fugir à propensão de tratar objetos e espaços de modo escópico, visual, formal, as matérias tocadas, quando postas em movimento, escapam ao toque, tornam-se intangíveis, pois que em constante transformação (ou, mais propriamente, porque se tornam o próprio vetor que determina a transformação).

Apesar dessa tendência a se figurarem como inconciliáveis, os três modelos de espacialidade encontram, na obra de Courtoisie, alternativas provisórias de equacionar seus antagonismos. Isto se dá por intermédio de imagens recorrentes que preservam a tensão olho/mão/movimento, forma/matéria/dinâmica. Tais imagens são: a música (ou a voz), o pó (ou a areia), a constelação (ou o coágulo) e a luz.

A voz pode ser entendida como instrumento criador de seu próprio espaço. Ao mesmo tempo, contudo, é também a negação do espaço, se se acredita que ela preenche o silêncio (este, na qualidade de condição e limite da voz, é que seria a imagem privilegiada de espaço). De qualquer modo, trata-se a voz como elemento sem substância, ou cuja substância, intensamente dinâmica, não ganha corpo; é o mero deslocamento de ar cujo conteúdo só pode ser hesitação, puros fluxo e expansão: espaço quase apenas musical. Em Courtoisie, a música, entendida segundo tal equação complexa, é muito presente: "Música de piedras y jugo de metales, agüitas virulentas acompañan la canción del mudo"; ${ }^{20}$ "Una música sin aire sostiene las columnas de Umbría". ${ }^{21}$

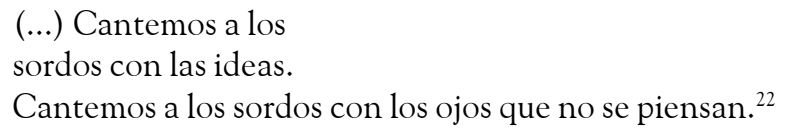

Na seguinte passagem do texto "El amor de los locos", se observa o caráter desafiador, talvez inescrutável, da música:

\footnotetext{
${ }^{18}$ COURTOISIE. Estado sólido, p. 22.

${ }^{19}$ COURTOISIE. Estado sólido, p. 29.

${ }^{20}$ COURTOISIE. Umbría, p. 23.

${ }^{21}$ COURTOISIE. Umbría, p. 49.

${ }^{22}$ COURTOISIE. Música para sordos, p. 21.
} 
El cerebro de un pájaro no pesa más que algunos gramos, y la parte que modula el canto es de un tamaño mucho menor que una cabeza de alfiler, un infinitésimo trocillo de tejido, de materia biológica que, con cierto aburrimiento, los sabios escrutan al miscroscopio para decifrar de qué manera, en tan exiguo retazo, está escrita la partitura. ${ }^{23}$

Similarmente à música, a imagem do pó, ou da areia, também conjuga, provisória e ambiguamente, os vetores espaciais mencionados: a invisibilidade visível (um grão de pó é quase uma abstração, um ponto, elemento puramente geométrico), a matéria desmaterializada, o movimento que não é autônomo, não se move por si, não tem poder de ação: "Un idioma de polvo se escucha en las calles"; 24 "Los hombres se construyen de arena." 25

Se o pó parece enfatizar, apesar de toda a ambivalência, a generalizada tendência à dispersão, encontra-se também em Courtoisie a tendência oposta: a que, a partir de um quadro de elementos descontínuos, precariamente reunidos, sugere a possibilidade de alguma configuração (portanto, de alguma forma, mesmo que estritamente hipotética e irreversivelmente incerta). Em tal tendência se situam as constelações, constituídas virtualmente por elementos cujas identidade e unidade são apenas efeitos temporários, como os coágulos: "Un hijo de palabras, hecho de coágulos, hecho de fragmentos de cosas que dije o que no dije"; ${ }^{26}$ "Un hombre se disuelve en su agua corporal como un terrón de sueño. No es sólido ni líquido y su vapor se esparce y pierde, a la larga, en actos y palabras. Momentáneamente sólido, momentáneamente erguido, un hombre es un grumo". ${ }^{27}$

¿Cómo será el hierro dentro del hierro?
Pienso en su alma
llena de nudos
pienso en una constelación musculosa,
en un tejido
de misterio donde cada fibra me recuerda
lo que soy:
mi fragilidad, mi blandura, mi invencible
debilidad. $^{28}$

A última imagem, a luz, também sintetiza o jogo conflituoso entre valores da espacialidade: a condição de visibilidade que não se confunde com o visível, os rudimentos de corporeidade que não se corporificam de todo, a potência de movimento tão exponencial que, para a escala humana, se passa por imobilidade, por acesso instantâneo, vitória sobre o tempo perceptível aos sentidos: "Una canción, en la aldea

\footnotetext{
${ }^{23}$ COURTOISIE. Estado sólido, p. 34.

${ }^{24}$ COURTOISIE. Umbría, p. 11.

${ }^{25}$ COURTOISIE. Música para sordos, p. 19.

${ }^{26}$ COURTOISIE. Umbría, p. 23.

${ }^{27}$ COURTOISIE. Estado sólido, p. 21.

${ }^{28}$ COURTOISIE. Música para sordos, p. 68.
} 
de los Ciegos, es el sol cada día. La voz ilumina las tareas y hasta los gallos de ojos vacíos responden ante esa luz audible",29 “iEl sol tiene cáscara?". ${ }^{30}$

Carne de la memoria

industria lenta del tiempo:

la luz despega su tegumento. ${ }^{31}$

Música, pó, coágulo, luz equacionam com nuanças distintas as relações, inescapáveis na obra de Courtoisie, entre a forma e o informe, o visível e o invisível, o concreto e o incorpóreo, a matéria e o impalpável, o móvel e o inativo, o estar e o deslocar. Têm em comum, porém, o fato de serem todas figuras da instabilidade. Esta se caracteriza, em especial, por recusar a lógica segundo a qual é imprescindível que um termo anule ou, pelo menos, prevaleça sobre o outro. A instabilidade se interessa justamente pela zona onde não se podem distinguir o que é possível e o que não é, zona em que princípios supostamente inatacáveis, como a irreversibilidade do tempo, a causalidade, a própria existência, podem ser sumariamente desacatados.

Dessa maneira se torna viável afirmar com impressionante confiança (que se nutre justamente do descrédito previsto no interlocutor): "Una carta llega a destino antes de ser escrita"; 32 ou: "Las voces actúan sobre las cosas, tienen una incidencia directa a pesar de que el principio de causalidad está alterado. Una palabra es causa de muchos objetos, los sostiene sobre un abismo de indefinición, los suspende sobre materias brumosas." ${ }^{33}$

A voz, ciosa da irreverência que a instabilidade lhe confere, pode enunciar (à maneira de um projeto poético-científico-filosófico, de uma intenção que já é realidade ou de uma conclusão que não passa de potencialidade pura; em suma, à maneira de um princípio que é fim) as seguintes palavras:

MÚSICA PARA sordos, peines para las piedras. Pensar imposibles es bueno.

Basta que un árbol no exista para que crezca. ${ }^{34}$

${ }^{29}$ COURTOISIE. Umbría, p. 18.

${ }^{30}$ COURTOISIE. Música para sordos, p. 43.

${ }^{31}$ COURTOISIE. Música para sordos, p. 15.

${ }^{32}$ COURTOISIE. Umbría, p. 7.

${ }^{33}$ COURTOISIE. Umbría, p. 10.

${ }^{34}$ COURTOISIE. Música para sordos, p. 13. 
A B S T R A C T

The work of the uruguayan writer Rafael Courtoisie is taken as starting point for a reflection on some models by which contemporary literature exercises what we consider to assign, generically, as "spatiality". This term does not concern to the way that literary text represents extraliterary spaces. Actually, it goes on the contrary direction, making possible that, in the scope of literature, one might deeply question what is understood as space. The three models of spatiality that we approach are: sight, touch and movement. The following books of Courtoisie have been selected: Estado sólido (1996), Umbría (1999) and Música para sordos (2002).

\section{KEYWORDS}

Space. Spatiality. Rafael Courtoisie. Contemporary

literature. Latin American literature.

\section{REFERÊNCIAS}

COURTOISIE, Rafael. Estado sólido. Madrid: Visor, 1996.

COURTOISIE, Rafael. Umbría. Caracas: Eclepsidra, 1999.

COURTOISIE, Rafael. Música para sordos. Tuxtla Gutiérrez: Gobierno del Estado de Chiapas, 2002. 